\title{
Neuralgia do Trigêmeo: uma revisão sistemática
}

Os ataques paroxísticos de dor lancinante caracterizam a neuralgia do trigêmeo, uma manifestação clínica de uma afecção do ramo maxilar. É considerada uma das dores mais graves insuportáveis descritas pela medicina, podendo, inclusive, levar ao suicídio. Há grande dificuldade em se realizarem trabalhos terapêuticos controlados na neuralgia do trigêmeo, pois os casos são infrequentes e é inaceitável não tratar o paciente de um grupo-placebo. Por isso, o trabalho em questão objetiva realizar uma revisão sistemática sobre os relatos e descrições existentes nas revistas científicas. O presente estudo consistiu em uma revisão sistemática da literatura, com síntese e análise dos achados clínicos e meta-análise sobre os dados quantitativos disponíveis em artigos de periódicos indexados, tanto do Brasil como de outros países. A neuralgia trigeminal é uma afecção com mecanismos fisiopatológicos não inteiramente esclarecidos. A terapia medicamentosa é considerada o tratamento de primeira linha para a NT. O anticonvulsivante carbamazepina tem sido usado desde 1960 por sua eficácia em aproximadamente $60 \%$ a $80 \%$ dos pacientes.

Palavras-chave: Anatomia; Neuralgia do trigêmeo; Tratamento.

\section{Trigeminal neuralgia: a systematic review}

Paroxysmal attacks of excruciating pain characterize trigeminal neuralgia, a clinical manifestation of an affection of the maxillary branch. It is considered one of the most severe and unbearable pains described by medicine, and can even lead to suicide. There is great difficulty in carrying out controlled therapeutic work on trigeminal neuralgia, as the cases are infrequent and it is unacceptable not to treat the patient in a placebo group. For this reason, the work in question aims to carry out a systematic review of the reports and descriptions existing in scientific journals. The present study consisted of a systematic review of the literature, with synthesis and analysis of clinical findings and meta-analysis of the quantitative data available in articles from indexed journals, both in Brazil and in other countries. Trigeminal neuralgia is a condition with pathophysiological mechanisms not fully understood. Drug therapy is considered the first-line treatment for NT. The anticonvulsant carbamazepine has been used since 1960 for its effectiveness in approximately $60 \%$ to $80 \%$ of patients.

Keywords: Anatomy; Trigeminal neuralgia; Treatment.

Topic: Neurologia e Neurociências

Reviewed anonymously in the process of blind peer.
Received: 18/08/2021

Approved: 15/09/2021
Bruno José Santos Lima

Universidade Tiradentes, Brasil

http://lattes.cnpq.br/6158584238563073

brunohd123456@gmail.com

\section{Maylla Fontes Sandes (iD}

Universidade Tiradentes, Brasil

http://lattes.cnpq.br/8288542250707046

http://orcid.org/0000-0002-5511-0253

sandesmaylla@gmail.com

\section{Débora Silva Pereira (ic}

Universidade Tiradentes, Brasil

http://lattes.cnpq.br/7598931407388639

http://orcid.org/0000-0001-7658-440X

debora.dspe@gmail.com

\section{Angela Santos Lima (iD}

Universidade Tiradentes, Brasil

http://lattes.cnpq.br/6236914921601084

http://orcid.org/0000-0001-9730-2934

angela slima@hotmail.com
Catharina Garcia de Oliveira (D)

Universidade Tiradentes, Brasil

http://lattes.cnpq.br/7374867085197930

http://orcid.org/0000-0001-6015-7323

catharinagoli@gmail.com

Gabriel Dantas Lopes (iD

Universidade Tiradentes, Brasil

http://lattes.cnpq.br/1412495355733136

http://orcid.org/0000-0002-9743-6825

gabrieldantaslopes@gmail.com

Ana Isabel Machado de Freitas

Universidade Tiradentes, Brasil

http://lattes.cnpq.br/1398967201909954

http://orcid.org/0000-0003-0506-0507

anaisabelmf96@gmail.com
Fernanda Bastos Santos (D)

Universidade Tiradentes, Brasil

http://lattes.cnpq.br/1777096204325089

http://orcid.org/0000-0003-4040-1901

fernanda.bastos97@souunit.com.br

Mariana Alma Rocha de Andrade

Universidade Tiradentes, Brasil

http://lattes.cnpq.br/2272348219459394

http://orcid.org/0000-0002-3516-6997

marianarochandrad@gmail.com

Leonardo Santos Melo (iD

Universidade Tiradentes, Brasil

http://lattes.cnpq.br/3797994277532039

http://orcid.org/0000-0003-0486-6031

lekosm11@gmail.com

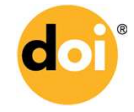

DOI: 10.6008/CBPC2236-9600.2021.003.0018

\section{Referencing this:}

LIMA, B. J. S.; SANDES, M. F.; PEREIRA, D. S.; LIMA, A. S.; OLIVEIRA, C. G.; LOPES, G. D.; FREITAS, A. I. M.; SANTOS, F. B.; ANDRADE, M. A. R.; MELO, L. S.. Neuralgia do Trigêmeo: uma revisão sistemática. Scire Salutis, v.11, n.3, p.136-141, 2021. DOI:

http://doi.org/10.6008/CBPC2236-9600.2021.003.0018 


\section{INTRODUÇÃO}

Os ataques paroxísticos de dor lancinante caracterizam a neuralgia do trigêmeo, uma manifestação clínica de uma afecção do ramo maxilar. É considerada uma das dores mais graves e insuportáveis descritas pela medicina, podendo, inclusive, levar ao suicídio. É descrita como dor latejante, em queimação ou em forma de choque elétrico, agulhada ou facada.

A incidência anual da neuralgia do trigêmeo é de 4,3 por 100.000 na população geral, com discreta predominância no sexo feminino (3:2). 0 pico de aparecimento é de 60 a 70 anos de idade, sendo incomum antes dos 40 anos. Pacientes hipertensos apresentam maior risco de desenvolver neuralgia do trigêmeo que a população em geral. Cerca de 80 a $90 \%$ dos casos classificados como idiopáticos são causados por compressão do nervo trigêmeo (5 par craniano) imediatamente na sua saída do tronco encefálico por uma alça aberrante arterial ou venosa, principalmente a artéria cerebelar superior.

Love et al. (2001) descrevem que os ataques dolorosos são frequentemente, mas nem sempre, precipitados por estímulos sensoriais leves (não nociceptivos) nas chamadas zonas de gatilho, que pode ser na pele, na mucosa ou no próprio dente. As zonas de gatilho podem estar localizadas em qualquer lugar dentro do território inervado pelo ramo neural afetado. Estímulos típicos que podem desencadear o ataque doloroso incluem o ato de falar, mastigar, beber, escovar os dentes, lavar o rosto, fazer a barba, maquiar e até mesmo o toque de uma brisa leve no rosto. Após a descarga dolorosa, existe um período refratário, durante o qual a estimulação da zona gatilho é ineficaz, cuja duração dependerá do paroxismo doloroso que o precedeu.

As afecções mais comumente envolvidas no diagnóstico diferencial são: cefaleia em salvas, dor dentária, arterite de células gigantes, neuralgia de nervo glossofaríngeo, tumor intracraniano, migrânea, esclerose múltipla, otite média, hemicrania paroxística, neuralgia pós-herpética, sinusite, cefaleia, síndrome da articulação temporomandibular e neuropatia trigeminal.

Há grande dificuldade em se realizarem trabalhos terapêuticos controlados na neuralgia do trigêmeo, pois os casos são infrequentes e é inaceitável não tratar o paciente de um grupo-placebo. A carbamazepina é o fármaco de escolha para o tratamento inicial da neuralgia trigeminal. Seu NNT (número necessário para tratar) é de 2,5, e sua dose varia de 100 a 2.400 mg por dia; a maioria dos casos responde com 200 a 800 mg por dia divididos em duas a três doses. Por isso, o trabalho em questão objetiva realizar uma revisão sistemática sobre os relatos e descrições existentes nas revistas científicas.

\section{METODOLOGIA}

O presente estudo consistiu em uma revisão sistemática da literatura, com síntese e análise dos achados clínicos e meta-análise sobre os dados quantitativos disponíveis em artigos de periódicos indexados, tanto do Brasil como de outros países. Artigos publicados em revistas indexadas foram considerados elegíveis se consistissem em relatos de caso e estudos que descrevem as características clínicas e métodos de diagnóstico que são usados para identificar a neuralgia do trigêmeo. Não houve 
restrições quanto ao ano em que o estudo foi desenvolvido ou publicado, o idioma ou o país onde o estudo foi realizado.

Os tipos de publicações incluídas foram artigos completos, curtos comunicações e relatos de casos que abordaram questões dentro dos seguintes critérios: (I) informações sobre a origem anatômica da neuralgia trigeminal; (II) a inervação da doença; (III) a patologia; e/ou (IV) o tratamento. Avaliações da literatura, notas de pesquisa, editoriais, ensaios experimentais e outros tipos de publicações fora dos critérios de inclusão foram excluídos.

Considerando os critérios de inclusão pré-estabelecidos, o processo de identificação de artigos foi desenvolvido utilizando o PubMed, SciELO, Bancos de dados ScienceDirect, Scopus e Web of Science. As buscas foram realizadas sem descrição de data. Uma ferramenta de gerenciamento bibliográfico foi usada para excluir duplicatas registros. Por meio dessa avaliação completa dos textos, outros estudos foram excluídos porque não atendiam à elegibilidade critério.

\section{DISCUSSÃO TEÓRICA}

O nervo trigêmeo, é classificado como $V$ par de nervos craniano, misto, com três ramos que suprem a região da face, entre estes estão o nervo oftálmico, nervo maxilar e nervo mandibular (Figura 1). A anatomia descreve que três grandes nervos surgem do bordo convexo do gânglio semilunar: o nervo oftálmico, nervo maxilar e nervo mandibular (Figura 2). O nervo oftálmico, primeira divisão do nervo trigêmeo, um nervo sensitivo. Menor das três divisões, dirige-se para frente penetrando na orbita através da fissura orbital superior. O nervo maxilar, segunda divisão do nervo trigêmeo, também sensitivo. Inicia na porção mediana do gânglio semilunar, deixando o crânio através do forame redondo. O nervo mandibular, maior das três divisões do nervo Trigêmeo, formado por duas raízes. Uma grande raiz sensitiva, derivada do gânglio semilunar, e uma raiz motora, que passa por baixo do gânglio, unindo com a raiz sensitiva. Segundo Madeira (2009), maioria dos neurônios originados da porção maior do nervo trigêmeo está agrupada no gânglio trigeminal, que é a maior massa ganglionar do corpo.

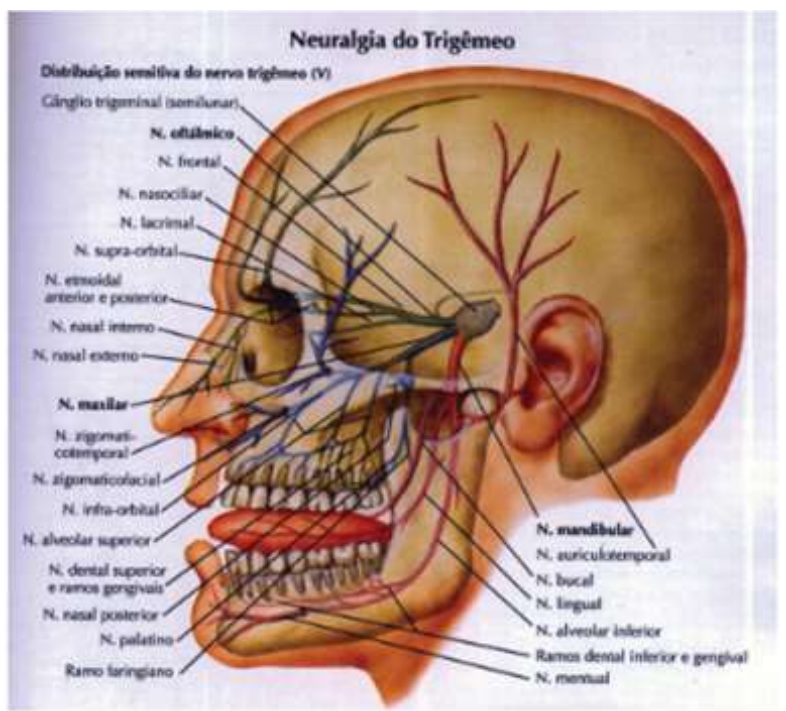

Figura 1: Distribuição sensitiva dos três ramos neurais que compõem o nervo trigêmeo: nervo oftálmico (verde); ramo maxilar (azul) e ramo mandibular (vermelho). Fonte: Jones Junior (2006). 
Figura 2: Zonas de intervenção cutânea das divisões do nervo trigêmeo, onde a dor pode ocorrer na neuralgia do trigêmeo. Fonte: Jones Junior (2006).

O primeiro ramo do nervo trigêmeo, o oftálmico, é responsável pela inervação da fronte, do nariz e das regiões oftálmicas da face. Ele deixa o crânio através da fissura orbitária superior na parte óssea da órbita. Tanto o ramo oftálmico quanto o ramo maxilar do nervo trigêmeo (trigémeo) inervam a cartilagem nasal com ramos terminais. O segundo ramo, o maxilar, fornece receptores nervosos para a face abaixo dos olhos e para a região maxilar. Uma importante ramificação do nervo maxilar é o nervo alveolar superior, que inerva os dentes da arcada superior no interior da cavidade oral. 0 terceiro ramo do nervo trigêmeo, o mandibular, é responsável pela sensibilidade da porção mais inferior da face, a região da mandíbula e o assoalho da cavidade oral. Além disso, ele fornece ramos motores para todos os músculos mandibulares, incluindo os músculos envolvidos na mastigação. Um importante ramo que inerva a língua é o nervo lingual.

A neuralgia trigeminal é uma afecção com mecanismos fisiopatológicos não inteiramente esclarecidos. Ainda não foi definido um único fator etiológico que, absolutamente, possa ser responsável pelo surgimento da neuralgia trigeminal, mas muitas afecções têm sido destacadas. Dentre elas, a compressão intracraniana do nervo trigêmeo por vasos periféricos, geralmente artérias. Outras causas incluem infecções viróticas, lesões tumorais, escleroses múltiplas, aneurismas e comprometimento alveolar pós-extração dentária.

Segundo Türp et al. (1966), o mecanismo que estaria próximo do que realmente ocorreria seria a conjunção de processos degenerativos do envelhecimento associados à compressão vascular, agindo durante vários anos, sobre a raiz posterior do nervo trigêmeo. A nevralgia trigeminal pode ainda estar relacionada tardiamente à terapêutica incorreta em traumatismos maxilofaciais, como por esmagamento ou fraturas dos ossos da face, destacando-se as fraturas do complexo zigomático-maxilar, principalmente quando envolvido o soalho da órbita, lesando o feixe vásculo-nervoso infra-orbitário.

O nervo trigêmeo ( $V$ par craniano) é considerado nervo misto, contendo fibras sensitivas (aferentes) e motoras (eferentes), sendo as primeiras de interesse ao quadro nevrálgico, responsáveis pela sensibilidade propioceptiva (pressão profunda e cinestesia) além de exteroceptiva (tato, dor e temperatura) da face e parte do crânio, inervando, ainda, os músculos responsáveis pela mastigação. Ao gânglio de Gasser, chegam as fibras sensitivas relacionadas ao estiramento e à propiocepção. Tais fibras 
chegam ao gânglio a partir das três ramificações do nervo (maxilar, mandibular e oftálmico) que possuem áreas específicas de inervação de cada lado da face (CARPENTER5, 1978; BRODAL4, 1984).

Em geral, a neuralgia do trigêmeo é unilateral acometendo, em ordem de frequência, o ramo maxilar (35\%), o mandibular (30\%), os ramos maxilar e mandibular (20\%), os ramos oftálmico e maxilar (10\%), o ramo oftálmico (4\%) e todos os ramos trigeminais (1\%). Dentre a incidência de casos $(4,3$ por 100.000/ano), cerca de 3\% são bilaterais. Os critérios diagnósticos são definidos pela IASP (International Association for the Study of Pain) e pela ICHD/IHS (International Classification of Headache Disorders/International Headache Society), sendo os seguintes: Ataques paroxísticos de dor com duração de uma fração de segundo a dois minutos, afetando uma ou mais divisões do nervo trigêmeo; A dor tem pelo menos uma das seguintes características: a) intensa, súbita, superficial ou em facada; b) precipitada por fatores-gatilho ou de áreas-gatilho; Os ataques são similares entre os pacientes; Nenhum distúrbio neurológico é clinicamente evidente; Não é atribuído a outra desordem.

Deve-se estar sempre atento para alguns sinais e sintomas atípicos que alertam para doenças subjacentes, como: exame neurológico anormal; exame oral, odontológico ou otológico anormais; idade menor que 40 anos; sintomas bilaterais; tontura ou vertigem; perda ou distúrbio auditivo; dormência; duração da dor maior que dois minutos; dor fora da distribuição do nervo trigêmeo; e alterações visuais. Os exames de imagem são imperativos. O exame físico dos pacientes com neuralgia trigeminal clássica é predominantemente normal. Portanto, anormalidades sensoriais na área trigeminal, perda do reflexo corneano ou qualquer fraqueza nos músculos faciais devem levar o médico a considerar causas secundárias da neuralgia.

A terapia medicamentosa é considerada o tratamento de primeira linha para a NT. O anticonvulsivante carbamazepina tem sido usado desde 1960 por sua eficácia em aproximadamente $60 \%$ a $80 \%$ dos pacientes. A posologia é bastante variável, devendo ser adaptada a cada caso. Com relação à carbamazepina, deve-se iniciar com doses de $100 \mathrm{mg} / \mathrm{dia}$ com aumento gradual das doses a cada dois ou três dias, podendo chegar a $1.600 \mathrm{mg} / \mathrm{dia}$, observando-se os efeitos clínicos e a tolerabilidade (LUCENA, 1985). O intervalo entre as dosagens deve ser de oito em oito horas. Entretanto, os efeitos colaterais e a eventual perda de eficácia têm estimulado a pesquisa de outros fármacos. Apesar de um grande número deles já ter sido utilizado nesse tratamento, apenas o baclofeno, a pimozida e a lamotrigina foram alvos de ensaios clínicos controlados.

O tratamento cirúrgico somente deve ser considerado, quando o paciente não responde ou venha a tornar-se refratário à medicação sistêmica. Nestas situações, várias modalidades são preconizadas, incluindo procedimentos no gânglio de Gasser (termocoagulação por radiofrequência, compressão isquêmica por balão e gangliólise com glicerol) ou procedimentos periféricos. Na avaliação risco-benefício do tratamento medicamentoso comparado ao cirúrgico, os resultados geralmente estão a favor do primeiro. 


\section{CONCLUSÕES}

Em linhas gerais, a neuralgia do trigêmeo é uma patologia que causa uma das dores mais insuportáveis descritas pela literatura, podendo levar o paciente até ao suicídio. Os aspectos fisiopatológicos ainda permanecem obscuros, mas supõe-se que exista uma associação com lesão direta, via compressão intracraniana ou infecções.

Percebe-se que há grande dificuldade em se realizarem trabalhos terapêuticos controlados na neuralgia do trigêmeo, pois os casos são infrequentes e é inaceitável não tratar o paciente de um grupoplacebo. A carbamazepina é o fármaco de escolha para o tratamento inicial da neuralgia trigeminal. Seu NNT (número necessário para tratar) é de 2,5, e sua dose varia de 100 a 2.400 mg por dia; a maioria dos casos responde com 200 a 800 mg por dias divididos em duas a três doses.

\section{REFERÊNCIAS}

ALVES, T. C. A.; AZEVEDO, G. S.; CARVALHO, E. S..

Tratamento famacológico da neuralgia do trigêmeo: revisão sistemática e metanálise. Revista Brasileira de Anestesiologia, v.54, n.6, p.836-849, 2004.

BORBOLATO, R. M.; AMBIEL, C. R.. Neuralgia do Trigêmeo: aspectos importantes na clínica odontológica. Saúde e Pesquisa, v.2, n.2, p.201-208, 2009.

FRIZZO, H. M.; VERONESE, R. M.; HASSE, P. N.. Neuralgia do trigêmeo: revisão bibliográfica analítica. Revista de Cirurgia e Traumatologia Buco-Maxilo-Facial, v.4, n.4, p.212-217, 2004.

LOVE, S.; COAKHAM, H. B.. Trigeminal neuralgia: pathology and pathogenesis. Brain, v.124, n.12, p.2347-2360, 2001.
NISHIMORI, L. E.. Nevralgia do nervo trigêmeo: diagnóstico e tratamento. Revista Uningá Review, v.22, n.2, 2015.

OLIVEIRA, C. M. B.. Neuralgia do trigêmeo bilateral: relato de caso. Revista Brasileira de Anestesiologia, v.59, n.4, p.476480, 2009.

QUEIROZ, V. I. G.. Anatomia do nervo trigêmeo. In: FÓRUM DE INICIAÇÃO CIENTÍFICA DO CENTRO UNIVERSITÁRIO DE SANTA FÉ DO SUL. Anais. Santa Fé do Sul, 2013.

ZAKRZEWSKA, J. M.; LINSKEY, M. E.. Trigeminal neuralgia. BMJ, v.348, 2014.

A CBPC - Companhia Brasileira de Produção Científica (CNPJ: 11.221.422/0001-03) detém os direitos materiais desta publicação. Os direitos referem-se à publicação do trabalho em qualquer parte do mundo, incluindo os direitos às renovações, expansões e disseminações da contribuição, bem como outros direitos subsidiários. Todos os trabalhos publicados eletronicamente poderão posteriormente ser publicados em coletâneas impressas sob coordenação da Sustenere Publishing, da Companhia Brasileira de Produção Científica e seus parceiros autorizados. Os (as) autores (as) preservam os direitos autorais, mas não têm permissão para a publicação da contribuição em outro meio, impresso ou digital, em português ou em tradução. 